OPEN ACCESS

Edited by:

Youji Wang,

Shanghai Ocean University, China

Reviewed by:

Wei Xu,

Texas A\&M University Corpus Christi,

United States

Jianmin Zhao,

Yantai Institute of Coastal Zone

Research (CAS), China

*Correspondence:

Lingling Wang

wanglingling@dlou.edu.cn

Linsheng Song

Ishsong@dlou.edu.cn

Specialty section:

This article was submitted to

Aquatic Physiology,

a section of the journal

Frontiers in Physiology

Received: 13 March 2019

Accepted: 26 July 2019

Published: 13 August 2019

Citation:

Zhang Y, Liu Z, Song X, Huang S,

Wang $L$ and Song $L$ (2019) The

Inhibition of Ocean Acidification on

the Formation of Oyster Calcified Shell

by Regulating the Expression

of Cgchs1 and Cgchit4.

Front. Physiol. 10:1034.

doi: 10.3389/fphys.2019.01034

\section{The Inhibition of Ocean Acidification on the Formation of Oyster Calcified Shell by Regulating the Expression of Cgchs1 and Cgchit4}

\author{
Yukun Zhang ${ }^{1,2,3}$, Zhaoqun Liu'1,2,3, Xiaorui Song ${ }^{1,2,3}$, Shu Huang ${ }^{1,2,3}$, Lingling Wang 1,2,3,4* \\ and Linsheng Song ${ }^{1,2,3,4 *}$
}

' Liaoning Key Laboratory of Marine Animal Immunology, Dalian Ocean University, Dalian, China, ${ }^{2}$ Liaoning Key Laboratory of Marine Animal Immunology and Disease Control, Dalian Ocean University, Dalian, China, ${ }^{3}$ Dalian Key Laboratory of Marine Animal Disease Prevention and Control, Dalian Ocean University, Dalian, China, ${ }^{4}$ Functional Laboratory for Marine Fisheries

Science and Food Production Processes, Qingdao National Laboratory for Marine Science and Technology, Qingdao, China

The biosynthesis of a calcified shell is critical for the development of oyster larvae. This process can be severely inhibited by $\mathrm{CO}_{2}$-induced ocean acidification, causing mass mortality of oyster larvae. However, the underlying molecular mechanism of such process has not been well explored until now. In the present study, a homolog of chitin synthase (named as Cgchs1) and a homolog of chitinase (named as Cgchit4) were identified from the Pacific oyster Crassostrea gigas. The cDNA sequences of Cgchs1 and Cgchit4 were of $813 \mathrm{bp}$ and $2118 \mathrm{bp}$, encoding a putative polypeptide of 271 amino acids and 706 amino acids, respectively. There were a Chitin_synth_2 domain and a Glyco_18 domain in the inferred amino acid sequences of Cgchs1 and Cgchit4, respectively. Both Cgchs1 and Cgchit4 shared high sequence identity with their homologs in vertebrates. In addition, when oyster larvae were exposed to acidification treatment ( $\mathrm{pH} 7.4)$, their shell biosynthesis process was seriously restrained. The expression level of Cgchs1 mRNA was significantly suppressed while that of Cgchit4 was dramatically activated upon acidification treatment. Cgchs1 and Cgchit4 are critical enzymes for chitin metabolism, and such changes in their mRNA expression could result in the decrease of chitin content in oyster larvae's shells, which might lead to the failure of shell formation. Therefore, results in the present study suggested that acidified seawater might inhibit the formation of oyster calcified shell by suppressing the biosynthesis of chitin.

Keywords: ocean acidification, chitinase, chitin synthetase, shell formation, oyster larvae

\section{INTRODUCTION}

Marine molluscs, such as oysters and scallops, secrete calcified shells as a supporting frame for their bodies and for the protection from predators (Zhang et al., 2012; Hendriks et al., 2015). The biosynthesis of the larval shells is originated from a peculiar group of ectodermal cells in the early developmental stages of embryos, which are called shell gland (Bevelander and Nakahara, 1969; Kniprath, 1979). When the ectodermal cells are sunken to construct the shell gland, the surrounding 
cells begin to generate the outmost matrix shell layer, the periostracum (Eyster and Morse, 1984). The cells of shell gland region are then turned over from inside to outside, transforming into the mantle epithelium of larvae (Kniprath, 1979; Bielefeld and Becker, 1991). During this process, the periostracum spans the whole shell field epithelial surface, and only then, the crystalline calcium carbonate appears for the first time (Eyster, 1986). The onset of shell mineralization occurs during the trochophore larval stage, which is usually about $20 \mathrm{~h}$ post fertilization (Kniprath, 1981; Nudelman et al., 2006), and the shell is called the prodissoconch I (PDI) (Weiss et al., 2002). The bivalve PDI is enlarged until the embryo is entirely enfolded and able to close its two valves. Transformation into the motile D-shape larvae then occurs. The D-shape larvae enlarges PDI to form prodissoconch II (PDII) which is fully calcified (Carriker and Palmer, 1979; Waller, 1981).

In the past few decades, these crucial processes have been severely inhibited by ocean acidification (OA) (Orr et al., 2005; Waldbusser and Salisbury, 2014). The oceans absorb the excess $\mathrm{CO}_{2}$, and cause changes in oceanic chemistry, including increased levels of dissolved $\mathrm{CO}_{2}$, a reduction in $\mathrm{pH}$ from pre-industrial levels of 8.2 to a projected 7.8 in 2100 , and a reduction in the saturation state of biologically useful forms of $\mathrm{CaCO}_{3}$, especially aragonite and calcite (Sabine et al., 2004; Kerr, 2010). Compared with the adults, molluscan larvae are especially sensitive to OA during the hours to days-long bottleneck when initial shell (PDI) is formed during embryogenesis (Waldbusser et al., 2013; Talmage and Gobler, 2009). During calcification of PDI, the calcification surfaces are in greater contact with ambient seawater than during the following shell stages (Waldbusser et al., 2014). Before PDI shell formation, the larvae mainly depend on the maternal energy from eggs for survival. Failure of forming complete shell before exhausting the maternal energy reserves would result in eventual mortality of larvae (Barton et al., 2012). Therefore, a better understanding of how OA suppresses the formation of calcified shell during larval development of oysters will not only contribute to illustrate the stress response patterns of marine calcifiers upon OA, but also provide new insights into the shellfish ecological aquaculture industry in a fast-changing environment.

Chitin synthase and chitinase, the crucial enzymes for the metabolism of chitin, have been proved to be important in shell biosynthesis of bivalve larvae because the calcified shell is deposited at early D-shape larvae stage to cover the chitin shell of trochophore larvae (Weiss and Schonitzer, 2006; Zhang et al., 2012). For example, a homologous gene for chitin synthetase was identified from mussel Mytilus galloprovincialis, which was expressed in the early embryo and the shell forming tissue of larvae (Weiss et al., 2006). It was speculated that chitin synthesis contributed via signal transduction pathways to the implementation of hierarchical patterns into chitin mineralcomposites such as prismatic, nacre, and crossed-lamellar shell types (Schonitzer and Weiss, 2007). Meanwhile, it was found that the chitinase of pearl oyster Pinctada fucata might possess key function in the biomineralization of shell (Li et al., 2017). Similar results were also reported in C. gigas that chitinase could regulate the shell formation in larvae under the modulation of dopamine
(Liu et al., 2018). However, the correlation between OA and the expressions of chitinase and chitin synthetase has never been reported during the formation of calcified shell in oyster larvae.

In the present study, a chitinase (Cgchit4) and a chitin synthase (Cgchs1) were identified from the Pacific oyster C. gigas with the major objectives to (1) explore the alteration of their expression levels during larval development stages as well as under acidification treatments, (2) illustrate their involvements in the biosynthesis of calcified shell during larval development, and (3) reveal the underlying mechanisms of how acidified seawater influence the formation of oyster calcified shell.

\section{MATERIALS AND METHODS}

\section{Oyster Larvae, Acidification Treatment, and Sample Collection}

The Pacific oysters C. gigas (about 2-year old, averaging $150 \mathrm{~mm}$ in shell length) were collected from a local breeding farm in Dalian, Liaoning Province, China, and maintained in the aerated seawater at $20^{\circ} \mathrm{C}$ for 14 days before processing. Eggs and sperms were scraped from female and male individuals, respectively, and mixed together in a small tank of $10 \mathrm{~L}$ for fertilization. The fertilized eggs were observed with a microscope to see if the first polar body was formed at $15 \mathrm{~min}$ after fertilized. The fertilized eggs were observed again to see if the second polar body was formed at $90 \mathrm{~min}$ post fertilization. Then, the fertilized eggs were transferred into a larger tank containing $100 \mathrm{~L}$ of aerated seawater at $20^{\circ} \mathrm{C}$. Sample collection began at $12 \mathrm{~h}$ post fertilization (hpf) according to previous description (Kin et al., 2009; Zhou et al., 2012). Trochophore (12 hpf), early D-shape larvae (17 hpf), and D-shape larvae (24 hpf) were authenticated through microscopy and collected.

Trochophores collected at $12 \mathrm{hpf}$ were equally divided into three groups (three replicates for each group). Larvae without any treatment were designated as the control group $(\mathrm{pH}=8.10 \pm 0.05)$, while those in the moderate $\mathrm{CO}_{2}$ treatment group ( $\mathrm{pH} 7.8$ group) were bathed in acidified seawater $(\mathrm{pH}=7.80 \pm 0.05)$. In the severe $\mathrm{CO}_{2}$ treatment group ( $\mathrm{pH} 7.4$ group), the trochophore larvae were bathed in acidified seawater with $\mathrm{pH}$ value of $(7.40 \pm 0.05)$. The $\mathrm{pH}$ value of the $\mathrm{CO}_{2}$ exposure group was controlled using an acidometer (AiKB, Qingdao, China). Total alkalinity was measured by endpoint titration of $25 \mathrm{mmol} \mathrm{L}^{-1} \mathrm{HCl}$ on $50 \mathrm{~mL}$ samples. The total alkalinity in the $\mathrm{pH} 8.1, \mathrm{pH} 7.8$, and $\mathrm{pH} 7.4$ groups was $2849.1 \pm 14.5 \mu \mathrm{eq} \mathrm{kg} \mathrm{kg}^{-1}, 2416.3 \pm 125.1 \mu \mathrm{eq} \mathrm{kg} \mathrm{kg}^{-1}$ and $2110.6 \pm 75.3 \mu$ eq $\mathrm{kg}^{-1}$, respectively. And the partial pressure of $\mathrm{CO}_{2}$ was about $658.1 \pm 11.0 \mathrm{ppm}, 1217.3 \pm 11.6 \mathrm{ppm}$ and $2268.4 \pm 50.1 \mathrm{ppm}$ in $\mathrm{pH} 8.1, \mathrm{pH} 7.8$, and $\mathrm{pH} 7.4$ treatment groups, respectively, (Table 1). Larvae in the three groups were sampled at $12 \mathrm{~h}$ after treatment (at D-shape larvae stage). Each sample was added into $1 \mathrm{~mL}$ of TRIzol reagent in $1.5 \mathrm{~mL}$ EP tube for RNA isolations (Invitrogen, United States).

Larvae for whole-mount in situ hybridization (WMISH) were first narcotized by gradual addition of $7.5 \% \mathrm{MgCl}_{2}$, followed by fixation in fresh $4 \%$ paraformaldehyde (PFA) in $0.01 \mathrm{M}$ phosphate buffer saline (PBS) $(0.2 \mathrm{~g} \mathrm{KCL}, 8.0 \mathrm{~g} \mathrm{NaCl}, 2.9 \mathrm{~g}$ 
TABLE 1 | Parameters of the seawater in the present study.

\begin{tabular}{lrc}
\hline pH control & pCo $_{2}$ & Total alkalinity \\
\hline $8.10 \pm 0.05$ & $658.1 \pm 11.0 \mathrm{ppm}$ & $2849.1 \pm 14.5 \mu \mathrm{eq} \mathrm{kg}^{-1}$ \\
$7.80 \pm 0.05$ & $1217.3 \pm 11.6 \mathrm{ppm}$ & $2416.3 \pm 125.1 \mu \mathrm{eq} \mathrm{kg}^{-1}$ \\
$7.40 \pm 0.05$ & $2268.4 \pm 50.1 \mathrm{ppm}$ & $2110.6 \pm 75.3 \mu \mathrm{eq} \mathrm{kg}^{-1}$ \\
\hline
\end{tabular}

$\left.\mathrm{Na}_{2} \mathrm{HPO}_{4} .12 \mathrm{H}_{2} \mathrm{O}, 0.2 \mathrm{~g} \mathrm{KH}_{2} \mathrm{PO}_{4}, \mathrm{pH} 7.40\right)$ at $4^{\circ} \mathrm{C}$ for $3 \mathrm{~h}$ and washed three times (15 min for each time) with precold PBS. After fixation, the samples were dehydrated and stored in pure methanol at $-20^{\circ} \mathrm{C}$ for the subsequent WMISH. For the scanning electron microscopy (SEM) analysis, oyster larvae were pre-fixed in 4\% PFA before the addition of $5 \%$ glutaraldehyde and incubated at $24^{\circ} \mathrm{C}$ for $4 \mathrm{~h}$. The samples were rinsed twice with $0.1 \mathrm{M}$ cacodylate and dehydrated with graded acetone.

\section{Total RNA Extraction and cDNA Synthesis}

Total RNA was isolated from the oyster larvae using TRIzol reagent according to the standard protocol. The RNA concentration was measured on a NanoDrop 2000 reader (Thermo Fisher, United States), and the integrity and purity of RNA were examined by electrophoresis running in 1.0\% agarose gel. The total RNA was then treated with DNaseI (Takara, China) to remove trace DNA contamination. The synthesis of the first-strand cDNA was carried out with Promega M-MLV RT with oligo (dT)-adaptor priming according to the manufactory's protocol. The synthesis reaction was performed at $42^{\circ} \mathrm{C}$ for $1 \mathrm{~h}$, terminated by heating at $95^{\circ} \mathrm{C}$ for $5 \mathrm{~min}$. The synthesis reaction product of cDNA was stored at $-80^{\circ} \mathrm{C}$ for the subsequent SYBR Green fluorescent quantitative real-time PCR.

\section{Gene Cloning and Sequence Analysis}

Blastp analysis of all oyster protein sequences revealed that one sequence (CGI_10024867) was homologous to chitinase identified previously, and one sequence (CGI_10025283) was homologous to chitin synthase. The open reading frame (ORF) of $\mathrm{Cg}$ chs 1 and $\mathrm{Cg}$ chit4 were cloned from cDNA library using specific primers (P1, P2 and P3, P4, Table 2). The homology searches of the cDNA sequences and protein sequences of $\mathrm{Cgchs} 1$ and Cgchit4 were conducted with BLAST algorithm at the National Center for Biotechnology Information $(\mathrm{NCBI})^{1}$. The deduced amino acid sequence was analyzed with the Expert Protein Analysis System ${ }^{2}$. The protein domain was predicted with the simple modular architecture research tool (SMART) version $5.1^{3}$. Multiple sequence alignment of the Cgchs1 and Cgchit4 with other chitinases and chitin synthetases was created by the ClustalW multiple alignment program ${ }^{4}$ and multiple sequence alignment show program ${ }^{5}$.

${ }^{1}$ http://www.ncbi.nlm.gov/blast

${ }^{2}$ http://www.expasy.org

${ }^{3}$ http://www.smart.emblheidelberg.de/

${ }^{4}$ http://www.ebi.ac.uk/Tools/clustalw2/

${ }^{5}$ http://www.biosoft.net/sms/index.html
TABLE 2 | Sequences of the primers used in this study.

\begin{tabular}{|c|c|}
\hline Primer & Sequence $\left(5^{\prime}-3^{\prime}\right)$ \\
\hline \multicolumn{2}{|l|}{ Clone primers } \\
\hline P1 (Cgchs1-F) & CCAAATGAGTTCGTGGCTGA \\
\hline P2 (Cgchs1-R) & AAGACAAGATAACCTGAGGGGAT \\
\hline P3 (Cgchi4-F) & TCTCTAACGGACTCTATITATGCG \\
\hline P4 (Cgchit4-R) & TITCCACAATTTCAATGCCA \\
\hline \multicolumn{2}{|l|}{ RT-PCR primers } \\
\hline P5 (Cgchs1-RT-F) & AAGCCTCACACTITACCAGAA \\
\hline P6 (Cgchs1-RT-R) & TTGATACCAGACAATCGGACC \\
\hline P7 (Cgchit4-RT-F) & AACCCCGCCACCCCTAC \\
\hline P8 (Cgchit4-RT-R) & TATCCCGTTGCTCCGTTATCA \\
\hline P9 (Cg-EF-F) & AGTCACCAAGGCTGCACAGAAAG \\
\hline $\mathrm{P} 10$ (Cg-EF-R) & TCCGACGTATTTCTITGCGATGT \\
\hline \multicolumn{2}{|l|}{ WEISH primer } \\
\hline P11 (Cgchs1-WEISH-F1) & CСССTCAGGTTATCTTGTC \\
\hline P12 (Cgchs1-WEISH-R1) & CTGGGAAACTGTTGAATGT \\
\hline \multirow[t]{2}{*}{ P13 (Cgchs1-WEISH-F2) } & CCGTAATACGACTCACTATAGCCC \\
\hline & CTCAGGTTATCTTGTC \\
\hline \multirow[t]{2}{*}{ P14 (Cgchs1-WEISH-R2) } & CGGATITAGGTGACACTATAGCTG \\
\hline & GGAAACTGTTGAATGT \\
\hline P15 (Cgchit4-WEISH-F1) & AACTCGTGGACCAGGC \\
\hline P16 (Cgchiti4-WEISH-R1) & ATAAGGTACGCTाTGCTCT \\
\hline \multirow[t]{2}{*}{ P17 (Cgchit4-WEISH-F2) } & CCGTAATACGACTCACTATAGAAC \\
\hline & TCGTGGACCAGGC \\
\hline \multirow[t]{2}{*}{ P18 (Cgchit4-WEISH-R2) } & CGGATITAGGTGACACTATAGATAA \\
\hline & GGTACGCTTTGCTCT \\
\hline
\end{tabular}

\section{Scanning Electron Microscope}

Oyster larvae were collected and immersed in 2.5\% glutaraldehyde at $4^{\circ} \mathrm{C}$ overnight, and then resuspended twice with $0.1 \mathrm{M}$ methyl arsenate. After dehydrated in an ascending series of acetone, the larvae samples were coated with gold atoms, and their morphology was observed through scanning electron microscope at a voltage of 20-25 kv.

\section{Quantitative Real-Time PCR}

The expression levels of Cgchs1 and Cgchit4 in different developmental stages were measured by an ABI PRISM 7500 Sequence Detection System with a total volume of $25.0 \mu \mathrm{L}$, containing $12.5 \mu \mathrm{L}$ of SYBR Green Mix (Takara), $0.5 \mu \mathrm{L}$ of each primers $\left(10 \mu \mathrm{mol} \mathrm{L}^{-1}\right)$ (P5, P6 and P7, P8, Table 2), $2.0 \mu \mathrm{L}$ of CDNA, and $9.5 \mu \mathrm{L}$ of DEPC-water. The oyster EF (elongation factor) was used as internal control (Table 2). Dissociation curve analysis of amplification products was performed to confirm that only one PCR product was amplified and detected. The comparative average cycle threshold method was used to analyze the mRNA expression level of the immune-related genes according to Zhang et al. (2008). All data were given in terms of relative mRNA expression using the $2^{-\Delta \Delta \mathrm{Ct}}$ method (Livak and Schmittgen, 2001).

\section{Whole-Mount in situ Hybridization}

Eight probe primers (Table 2) were used to synthesize the RNA probe. The paired primers, P11 and P12, P15 and P16, were used to amplify the double-stranded DNA probe of chitin 
synthetase and chitinase, respectively. The T7 promoter sequence was added to the $5^{\prime}$ end of P13 and P17 primer, while the SP6 promoter sequence was added to $5^{\prime}$ end of P14 and P18. The double-stranded DNA probe with the T7/SP6 promoter sequence primer was amplified in order to add the promoter sequence for the in vitro transcription of single stranded RNA probe with T7/SP6 RNA polymerase and digoxin DIG RNA Labeling Mixture (Roche, Switzerland). The detailed step was conducted following the previously research (Thisse and Thisse, 2008).

\section{Statistical Analysis}

All the data were shown as mean \pm S.D. The two-sample student's tests were performed for the comparisons between groups. Multiple group comparisons were executed by one-way ANOVA and followed by a Turkey multiple group comparison tests using Statistical Package for Social Sciences (SPSS) 16.0 Software. The difference was considered as significant at $p<0.05$.

\section{RESULTS}

\section{Sequence Features and Phylogenetic Relationship Constructs of Cgchs1 and Cgchit4}

A potential oyster chitin synthase was screened out from the NCBI database with the GenBank accession number of XP_011422035.1 (Figure 1A). In the present study, an 813 bp cDNA fragment of Cgchs1 was amplified, which encoded a presumptive peptide of 271 amino acids. The predicted molecular weight of the derived $C g$ chs 1 protein was $30.16 \mathrm{kDa}$ with a Chitin_synth_2 domain (from Glu872 to Val1143) (Figure 1B) and its theoretical isoelectric point (pI) was 6.08. Meanwhile, a potential oyster chitinase ( $\mathrm{Cg}$ chit 4 ) with the GenBank accession NO. XP_011432127.1 was also annotated from oyster genome. A cDNA fragment of 2118 bp was amplified, which encoded Cgchit4 (706 amino acids) with the theoretical molecular weight of $80.43 \mathrm{kDa}$ (Figure 2A). The theoretical pI of Cgchit4 was 9.13 which predicted by Compute $\mathrm{pI} / \mathrm{Mw}$ tool of ExPasy. There was a Glyco_18 domain (from His81 to Asp426) found in Cgchit4 (Figure 2B).

The phylogenic trees were constructed by using the amino acid alignment of $C g$ chs1 and Cgchit4 (Figures 1C, 2C). There were two major distinct branches for the chs1 and chit 4 from vertebrate and invertebrate. The chitin synthase and chitinase from vertebrates were clustered together as a sister branch from invertebrate ones. Both Cgchs1 and Cgchit4 were primarily aggregated with their homologs from $C$. virginica and $M$. yessoensis, and then clustered with those from other invertebrate species (Figures 1C, 2C). The amino acid sequence of Cgchs1 shared $44 \%$ identity with chitin synthase from M. galloprovincialis, $43 \%$ identity with that from Drosophila melanogaster, $41 \%$ identity with that from D. rerio, $24 \%$ identity with that from $X$. laevis, and $22 \%$ identity with that from Homo sapiens. Multiple alignment analysis found that there were three motifs including QXXEY, EDRXL, and QXRRW in the Chitin_synth_2 domain of Cgchs1 (Figure 3A). The amino acid sequence of $C g$ chit 4 shared 52\% identity with chitinase from Mizuhopecten yessoensis, $51 \%$ identity with that from Chelonia mydas, $47 \%$ identity with that from Cyanistes caeruleus, and $41 \%$ identity with that from $H$. sapiens. An active site of FDGLDXDW was identified in the Glyco_18 domain of Cgchit4, which was similar with their homologs from vertebrate species (Figure 3B).

\section{The mRNA Expression Levels of Cgchs1 and Cgchit4 in Trochophore, Early D-Shape Larvae and D-Shape Larvae in Response to Acidification Treatment}

The expression levels of Cgchs1 and Cgchit4 mRNA were investigated in trochophore, early D-shape larvae and D-shape larvae in response to acidification treatment by quantitative real-time PCR. In the control group, the expression level of Cgchs1 mRNA at D-shape larvae stage was significantly lower comparing with that at trochophore and early D-shape larvae stages (Figure 4A, $p<0.05$ ), nevertheless the expression level of $C g$ chit 4 mRNA in early D-shape larvae was obviously higher than that in trochophore and D-shape larvae (Figure 4B, $p<0.05$ ). No distinct change of the mRNA expressions of Cgchs1 and $\mathrm{Cgchit} 4$ was observed after moderate acidification treatment $(\mathrm{pH}$ 7.8), while the expression level of Cgchs1 mRNA (Figure 4A, $p<0.05$ ) was significantly decreased and that of $C g$ chit 4 mRNA (Figure 4B, $p<0.05$ ) was significantly increased after the severe acidification treatment ( $\mathrm{pH} 7.4)$.

\section{Morphologic Observation of Oyster Larvae Shell Under Acidification Treatment}

Scanning electron microscopy was used for inspecting the morphological characteristics of oyster larvae under the different acidification treatments (Figure 5). A uniform and smooth shell appeared in oyster larvae from trochophore to D-shape larvae in the control group, exhibiting a normal developmental process. The sizes of larvae in control group and moderate acidification treatment were almost same, while the initial shell formation of larvae could be delayed in severe acidification treatment group. As shown in Figure 5, there was a small concave on the ventral edge of the initial shell of early D-shape larvae in the moderate acidification group (indicated by the white arrow). The initial shell of early D-shape larvae in the severe acidification group was not as smooth as that in the control group, and the shell length was also shorter (indicated by the white arrows). Besides, the initial shell of D-shape larvae in the severe acidification treatment group was full of wrinkles and the calcified layer was barely formed comparing with that in the control group (indicated by the while arrow).

\section{The Distribution of Cgchs1 and Cgchit4 mRNA Transcripts in Trochophore, Early D-Shape Larvae and D-Shape Larvae Under Acidification Treatment}

The localization of $C g$ chs 1 and $C g$ chit 4 mRNA transcripts in trochophore, early D-shape larvae and D-shape larvae under 


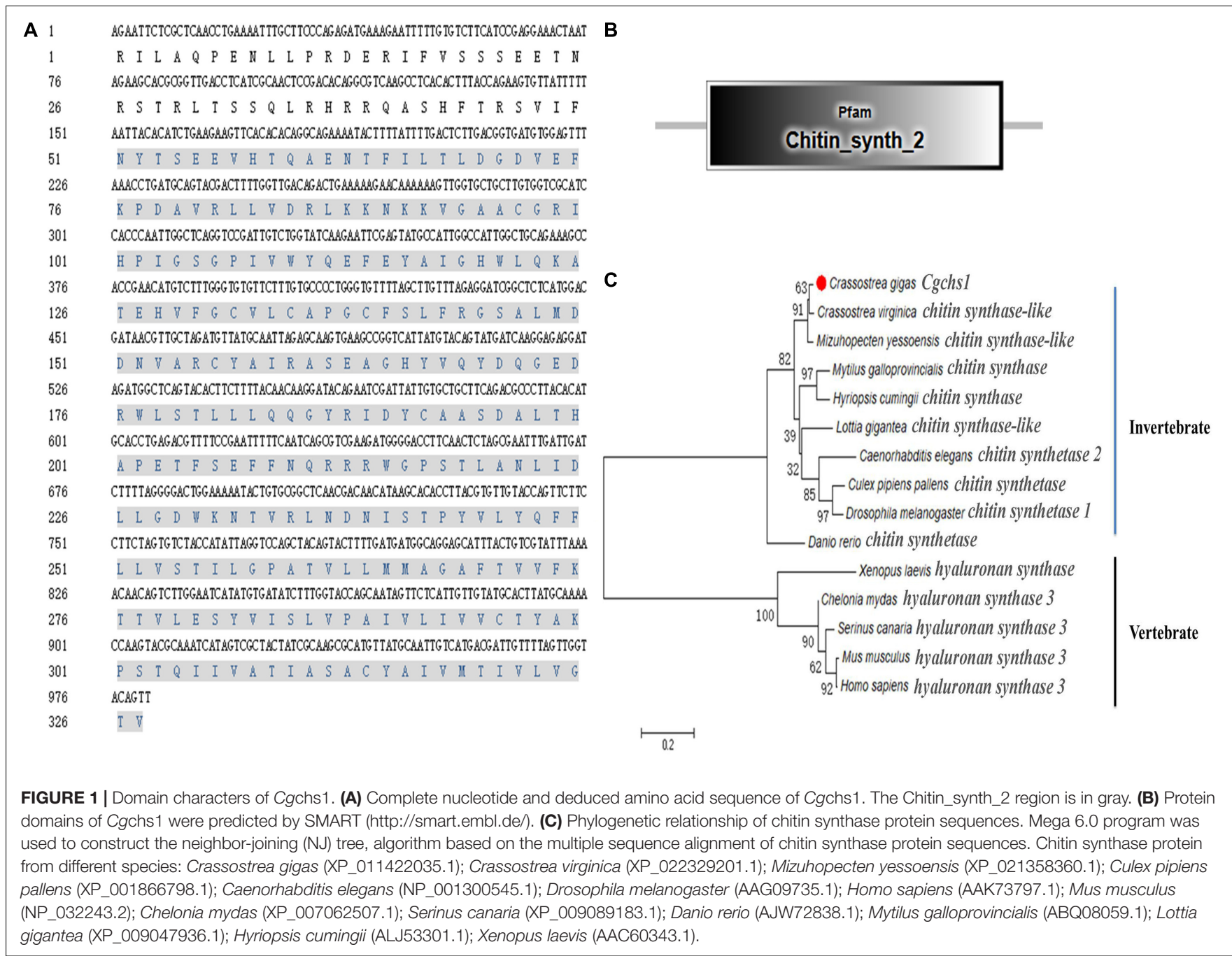

acidification treatment were investigated via WMISH. The positive signals were dyed in bluish violet, and they were mainly distributed on the edge of the newly formed shells. In both the control and acidification treatment trochophore larvae, the positive signal was mainly located on the margin of shell field in. And in D-shape larvae, the positive signal was found on the edge of periostracum. No specific signals were inspected in all over the negative control groups, suggesting the specificity of the antisense probes and the creditability of the current results (Figure 6).

\section{DISCUSSION}

As the exoskeletons for most molluscan species, shells have been extensively studied in both adults and larvae for their evolutionary and economic importance. The larval shell emerges early in embryogenesis of molluscs, and chitin biogenesis is crucial for this process (Peters, 1972). The ongoing $\mathrm{CO}_{2}$-induced ocean acidification has been reported to severely threaten the shell formation of molluscan larvae and cause mass mortality (Kurihara et al., 2007; Miller et al., 2009; Kroeker et al., 2010;
Talmage and Gobler, 2010; Parker et al., 2012). Previous studies have already demonstrated that the early development of bivalves including oyster C. gigas (Kurihara et al., 2007; Barros et al., 2013), blue mussel Mytilus edulis (Gazeau et al., 2010) and barnacle Amphibalanus amphitrite (McDonald et al., 2009) is negatively affected by acidified conditions. In the present study, a chitin synthase $(C g$ chs 1$)$ and a chitinase (Cgchit4) were identified from C. gigas. Their responses against acidification treatment during larval development stages were investigated to illustrate the impact of OA on the shell formation of oyster larvae by modulating the biogenesis of chitin.

Chitin synthase and chitinase were reported to be employed in many biological and physiological processes such as digestion (Mali et al., 2004), host defense (Boot et al., 1995, 2001), and most importantly, in biomineralization (Schonitzer and Weiss, 2007). In order to understand the modulation effect of chitin synthase and chitinase in shell formation, in the present study, a chitin synthase gene $(C g c h s 1)$ and a chitinase gene $(C g$ chit4) were identified from C. gigas. The length of Cgchs1 sequence was of $813 \mathrm{bp}$, encoding a putative peptide fragment of 271 amino acids with the theoretical molecular weight of $30.16 \mathrm{kDa}$. There was 


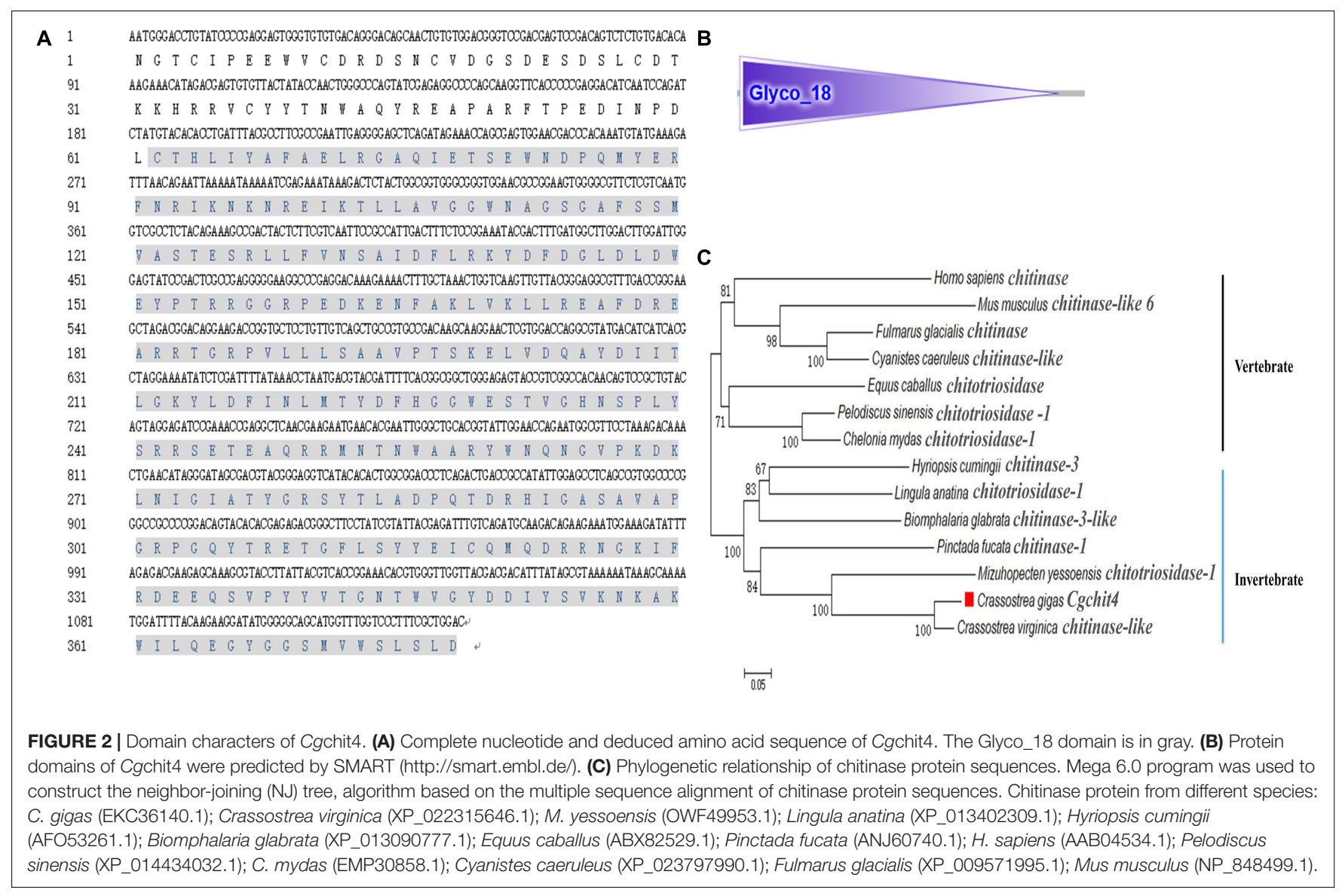

a Chitin_synth_2 domain in Cgchs1, which was the key domain to catalyze the chemical reaction (Sburlati and Cabib, 1986). Chitin synthases belong to the members of glycosyltransferases and consist of a transmembrane protein family with at least three transmembrane helices. The $\mathrm{N}$ - and $\mathrm{C}$-terminal residues of chitin synthetase possibly differ even in the isoforms from the same species, but these two lower complexity motifs contain plenty of acidic or basic residues which are the main characteristics for various molluscan chitin synthase. In addition, the catalytic site of intracellular is highly conserved which possesses the function of catalytic chitin synthesis and plays a key role in the precisely controlled mineral deposition process of other mollusk as well as Pacific oyster C. gigas (Marin et al., 2008; Schonitzer et al., 2011). As for Cgchit4, the full length of cDNA sequence was of $2118 \mathrm{bp}$, encoding a putative polypeptide of 706 amino acids with the theoretical molecular weight of 80.34. A Glyco_18 domain was included in the $\mathrm{Cg}$ chit4, which was important for the hydrolysis of the glucosidic bond of carbohydrates (Renkema et al., 1995). Cgchs1 shared high sequence similarity (42-44\%) with chitin synthase from other vertebrates and invertebrates. Phylogenic analysis also showed that $C g$ chs 1 was close to chitin synthase from invertebrates such as B. glabrata, M. yessoensis (Bulawa, 1992; Luo et al., 2015). Cgchit4 exhibited high sequence similarity (41-52\%) with chitinase from other vertebrates and invertebrates, and it was clustered with chitinases from invertebrates such as P. fucata and H. cumingii (Gao et al., 2014; Li et al., 2017). These results indicated that $C g$ chs 1 and $C g$ chit 4 might belong to the family of chitin synthase and chitinase in molluscs, respectively.

In order to investigate the possible function of Cgchs 1 and Cgchit4 in shell formation of oyster larvae, their mRNA expression levels and localization were detected by quantitative real-time PCR and WMISH, and the larval morphological characteristics were observed by SEM. The expression level of Cgchs1 mRNA was extremely lower at D-shape larvae compared with that at trochophore and early $\mathrm{D}$-shape larvae, while the expression level of $C g$ chit 4 mRNA in early D-shape larvae was distinctly higher than that at trochophore and D-shape larvae. As shown in Figure 5, a uniformly calcified shell was successfully formed from trochophore to D-shape larvae at control group. Similar results have also been reported from other molluscan species. It was found that the chitin synthase could be detected in the shell margin of larval M. galloprovincialis which was the region involved in shell extend in early developmental stage (Weiss et al., 2006). Chitin synthase and chitinase are the key enzymes for chitin shell biosynthesis in molluscs. Chitin synthase is in charge of the synthesis of chitin, while chitinase is responsible for the degradation of chitin (Weiss and Schonitzer, 2006; Weiss et al., 2006). Results of this study suggested that synthesis of chitin was down-regulated and the degradation of chitin was prompted at the stages from trochophore to early D-shape larvae, which might cause the content reduction of chitin in the shell of oyster larvae. These results were in consistent 
A

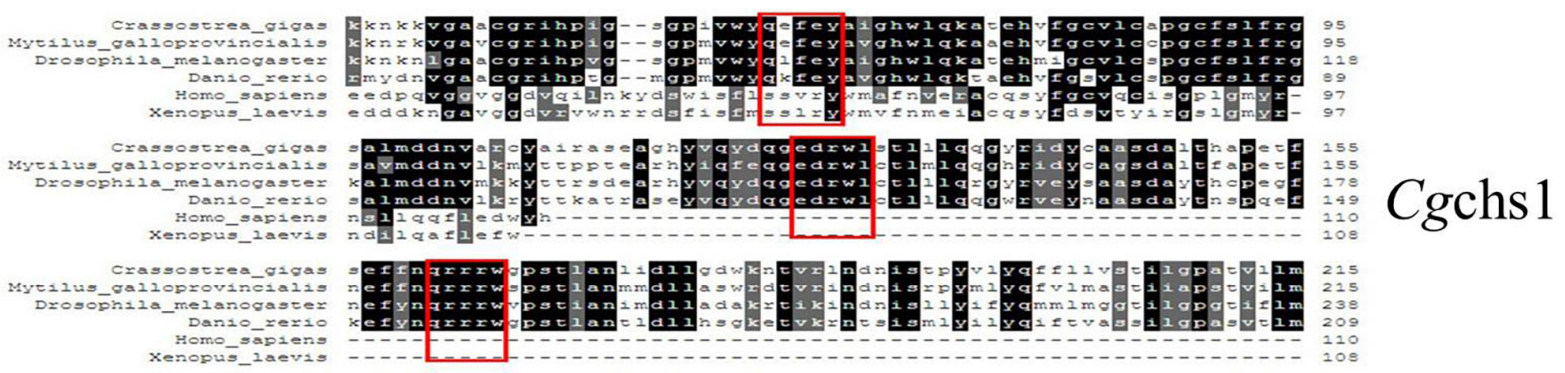

B

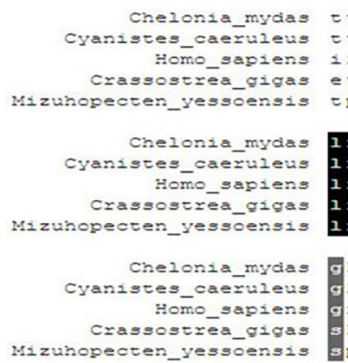

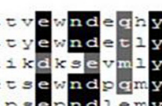
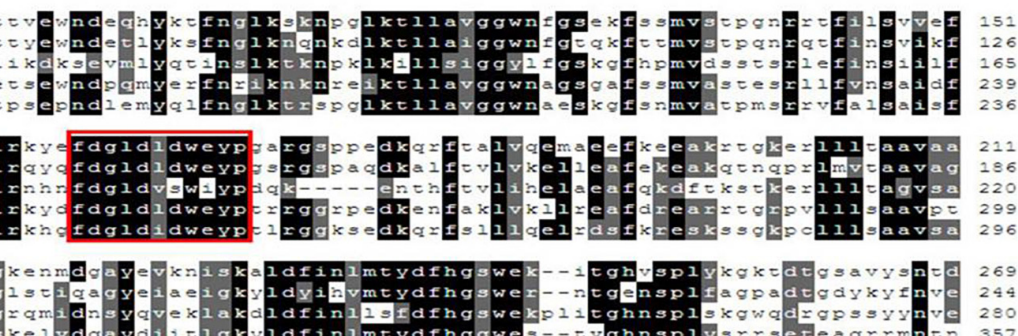

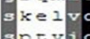
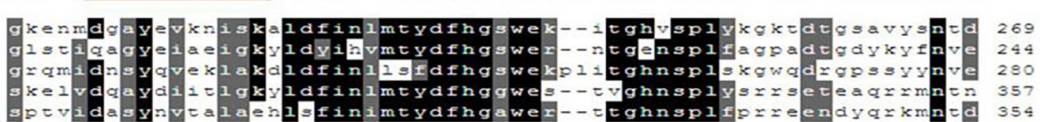

\section{Cgchit4}

FIGURE 3 | (A) Multiple sequence alignment of the Cgchs1 and Cgchit4 proteins. Multiple sequence alignment of Cgchs1 with chitin synthase from other species: C. gigas (XP_011422035.1); M. galloprovincialis (ABQ08059.1); Drosophila melanogaster (AAG09735.1); Danio rerio (AJW72838.1); H. sapiens (AAK73797.1); Xenopus laevis (AAC60343.1). (B) Multiple sequence alignment of Cgchit4 with known chitinases from other species: C. mydas (EMP30858.1); C. caeruleus (XP_023797990.1); H. sapiens (AAB04534.1); C. gigas (EKC36140.1); M. yessoensis (OWF49953.1). Red boxes showed the active site of FDGLDXDW in the Glyco_18 domain of Cgchit4.

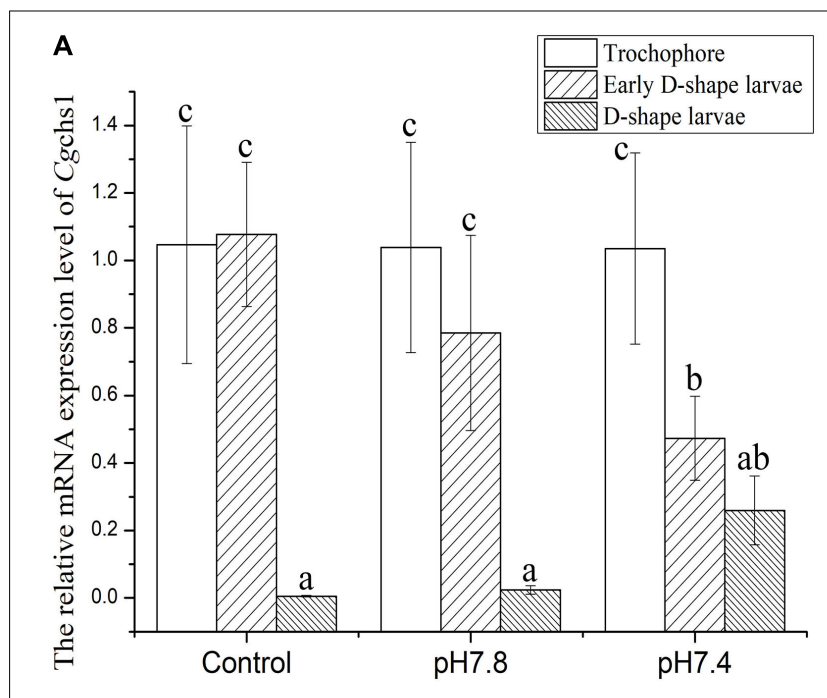

Different culture conditions

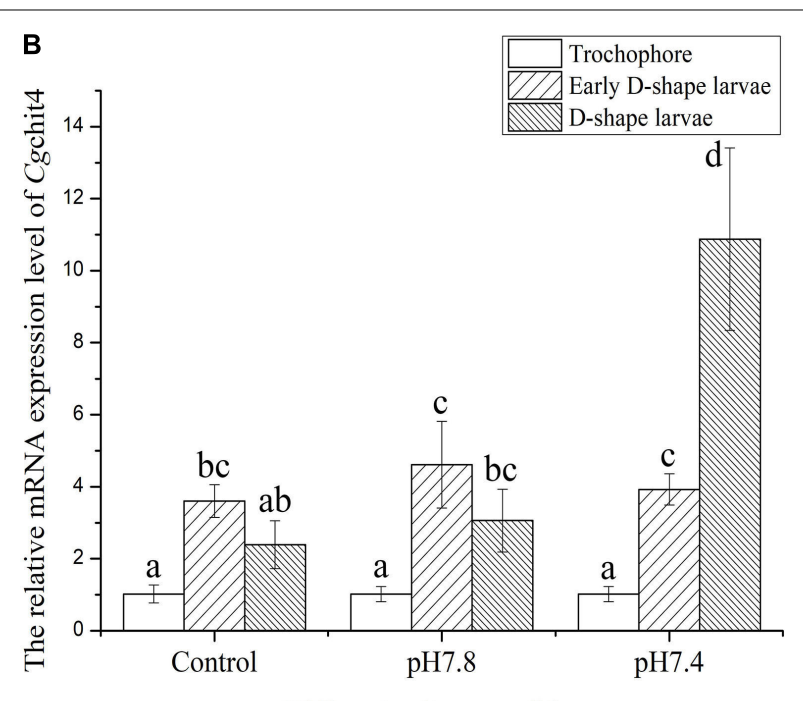

Different culture conditions

FIGURE 4 | The expression levels of Cgchs1 and Cgchit4 mRNA transcripts in trochophore, early D-shape larvae and D-shape larvae under different acidification treatment. Cgchs1 and Cgchit4 mRNA expression levels in different development stage and in different culture conditions of oyster $C$. gigas were detected by qRT-PCR. (A) Cgchs1 and Cgchit4 transcript levels in trochophore larvae, early D-veliger larvae and D-veliger larvae of three acidification treatment (control, pH 7.8, and $\mathrm{pH}$ 7.4) were normalized to that of in trochophore larvae, respectively. (B) Vertical bars represent the mean \pm S. D. $(N=3)$, and the letters (a,b,c) were used to present significant differences.

with previous findings that biomineralization was activated from trochophore to D-shape larvae in molluscs, resulting in the organic-mineral composite (mainly $\mathrm{CaCO}_{3}$ ) shell layer to cover the chitin framework one.
According to previous study, there are several hypotheses trying to explain how shell formations in oyster larvae are affected by OA. Some researchers considered that OA lowered the calcium carbonate saturation state, which caused oyster 


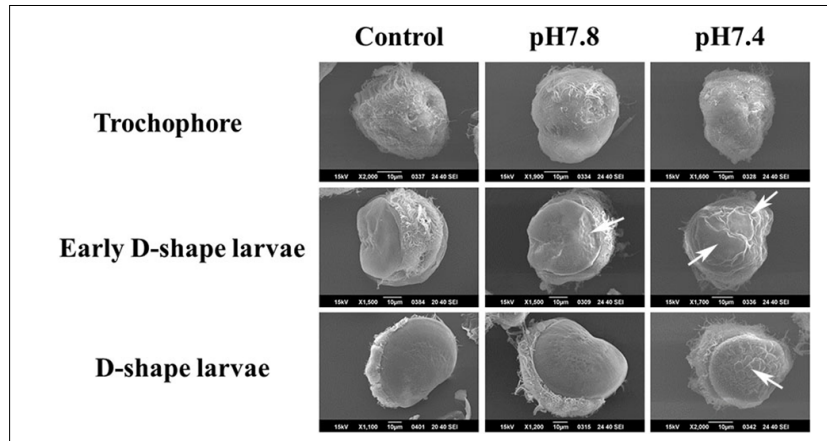

FIGURE 5 | Morphological characteristics of oyster larvae under acidification treatment. The oyster larvae from three different development stages treated with three different acidification treatments, respectively, were collected and observed by scanning electron microscope. Trochophore, Early D-shape larvae and D-shape larvae were employed for the acidification treatments, and they were divided into three different acidification (Control, $\mathrm{pH} 7.8$, and $\mathrm{pH}$ 7.4) groups, respectively. The white arrow showed the predicted location of shell malformation.

larvae harder to form the complete calcified shell. It was also believed that acidification upset the acid-base balance between the marine organism and environment, and even the inner acid-base balance of organism (Zhao et al., 2017), which influenced the energy metabolism and homeostasis in oyster larvae (Lannig et al., 2010). We are inclined to a hypothesis that OA might disturb the biosynthesis of chitin and finally invite the failure of shell formation in oyster larvae. In the present study, the expression of Cgchs1 and Cgchit4, and the morphological characteristics of oyster larvae under acidification treatment were explored. It was found that in the moderate acidification treatment $(\mathrm{pH}$ 7.8) group, the expression level of Cgchs1 mRNA was decreased slightly in early D-shape stage, while that of $C g$ chit4 mRNA was obviously decreased in early D-shape stage in the severe acidification treatment $(\mathrm{pH} 7.4)$ group. These results suggested that the synthesis of chitin was significantly inhibited by severe acidification treatment ( $\mathrm{pH} 7.4$ ), while the degradation of chitin was dramatically activated. As shown in Figure 5, the shell formation in oyster larvae was indeed significantly suppressed by severe acidification treatment. Chitin is proverbial as a crucial component in molluscan shell and nacre biosynthesis. Chitin constructed the initial shell basis and supplied for other macromolecular and mineral deposition that visibly guide the biomineralization process, even in the system of crystal polymorphism (Levi-Kalisman et al., 2001; Zentz et al., 2001). Results in current research implied that the inhibition of biosynthesis of chitin caused by acidification conditions might be the reason for the failure of shell formation from trochophore to D-shape larvae during ontogenesis of oyster.

Moreover, the structural organization of chitin synthesizing complex in oyster larvae was further explored under normal and acidification conditions with WMISH. As shown in Figure 6, the $C g$ chs 1 and $C g$ chit 4 mRNA was mainly expressed in the beneath of newly formed shells. In trochophore stage, the positive signal was mainly located on the margin of shell field. In D-shape larvae stage, the positive signal was found on the edge of periostracum.

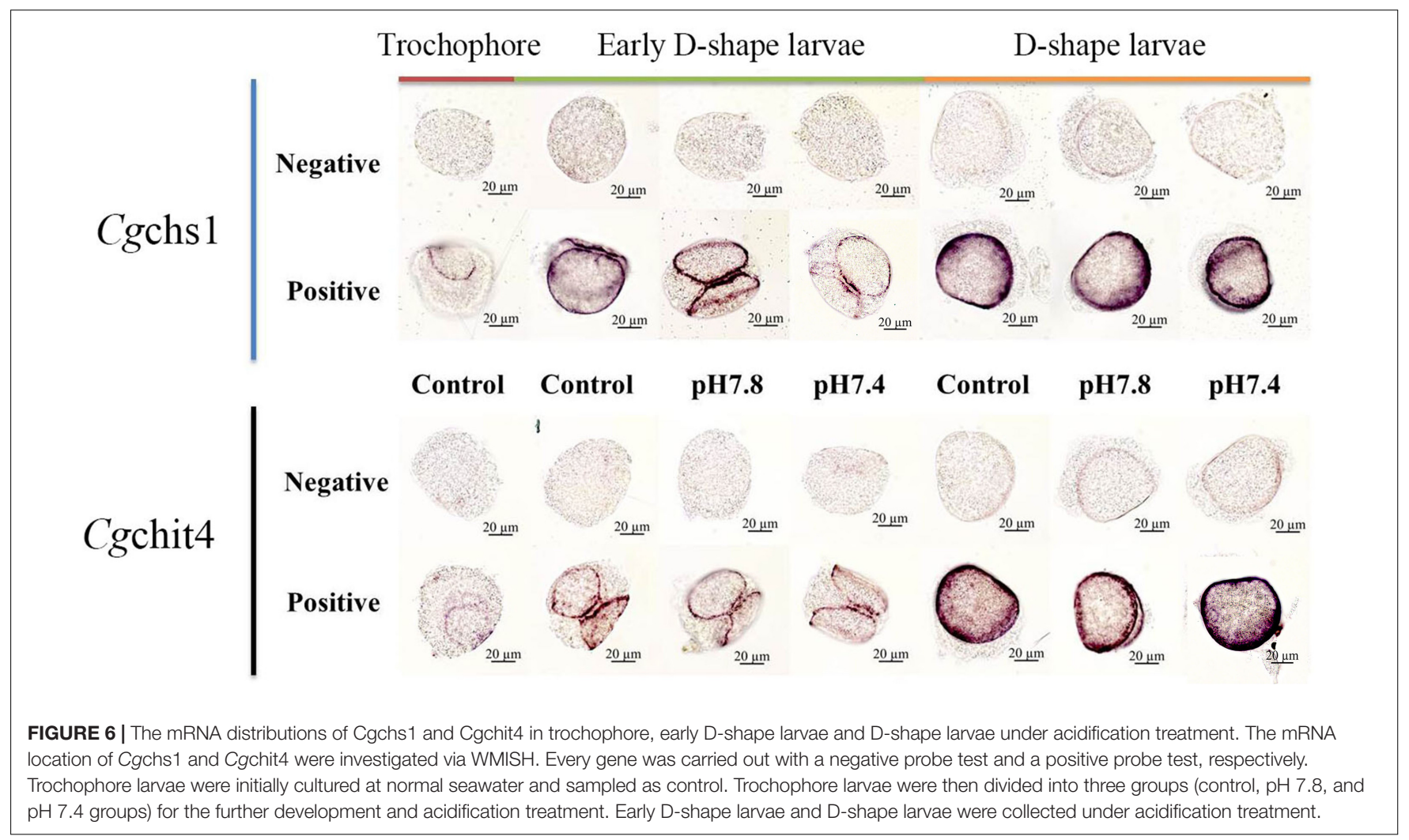


These consequences were consistent with the anterior studies that chitin synthase could be detected in the shell gland region and related to shell biosynthesis of $M$. galloprovincialis larvae, and the inhibition of chitin synthase through Nikkomycin $\mathrm{Z}$ could dramatically alter the shell structure and function, for instance the bivalve hinge and the shell margin (Schönitzer and Weiss, 2007). Another previous study reported that the calcification taken place on the margin of the shell, among mantle tissue, periostracum and the shell itself (Marin et al., 2012). Therefore, all these results collectively suggested that the shell biosynthesis process and intricate framework compounds structure in oyster larvae were located close to the edges of shell. Acidification treatment could severely inhibit the biosynthesis of chitin, resulting in the failure of biomineralization in oyster larvae.

\section{CONCLUSION}

In conclusion, a Cgchs1 and a Cgchit4 gene were identified from C. gigas, which belonged to chitin synthase and chitinase family, respectively. During the key developmental stages for shell formation, the chitin biosynthesis was decreased from trochophore to D-shape larvae since the down-regulated mRNA expression of $C g$ chs1, while the decomposition of chitin was accelerated due to the up-regulated mRNA expression level of $C g$ chit4. When oyster larvae suffered from $\mathrm{CO}_{2}$-induced acidification, the formation of calcified shell was severely inhibited, and the expression of Cgchs1 was significantly suppressed while that of Cgchit4 was dramatically activated, resulting in a decrease in chitin content on the edges of the shell. These results collectively suggested that OA might inhibit shell formation in oyster larvae by suppressing the biosynthesis of chitin.

\section{DATA AVAILABILITY}

The raw data supporting the conclusions of this manuscript will be made available by the authors, without undue reservation, to any qualified researcher.

\section{REFERENCES}

Barros, P., Sobral, P., Range, P., Chícharo, L., and Matias, D. (2013). Effects of sea-water acidification on fertilization and larval development of the oyster Crassostrea gigas. J. Exp. Mar. Biolecol. 440, 200-206. doi: 10.1016/j.jembe.2012. 12.014

Barton, A., Hales, B., Waldbusser, G. G., Langdon, C., and Feely, R. A. (2012). The Pacific oyster, Crassostrea gigas, shows negative correlation to naturally elevated carbon dioxide levels: implications for near-term ocean acidification effects. Limnol. Oceanogr. 57, 698-710. doi: 10.4319/lo.2012.57.3.0698

Bevelander, G., and Nakahara, H. (1969). An electron microscope study of the formation of the nacreous layer in the shell of certain bivalve molluscs. Calcif. Tissue Res. 3, 84-92. doi: 10.1007/bf02058648

Bielefeld, U., and Becker, W. (1991). Embryonic development of the shell in biomphalaria glabrata (Say). Int. J. Dev. Biol. 35, 121-131.

Boot, R. G., Blommaart, E. F., Swart, E., Ghauharali-Van Der Vlugt, K., Bijl, N., Moe, C., et al. (2001). Identification of a novel acidic mammalian chitinase

\section{ETHICS STATEMENT}

This study was carried out in accordance with the recommendations of the Ethics Committee of Dalian Ocean University. The protocol was approved by the Ethics Committee of Dalian Ocean University.

\section{AUTHOR CONTRIBUTIONS}

YZ, ZL, XS, SH, and LW conceived and designed the experiments. YZ, ZL, and XS performed the experiments. YZ and ZL analyzed the data. LW and LS contributed reagents, materials, and analysis tools. YZ, ZL, LW, and LS wrote the manuscript. All authors read and approved the final manuscript.

\section{FUNDING}

This research was supported by the National Key R\&D Program (2018YFD0900606), by a grant (No. U1706204) from the National Science Foundation of China, Key R\&D Program of Liaoning Province (2017203001 to LW), earmarked fund (CARS-49) from the Modern Agro-industry Technology Research System, the Fund for Outstanding Talents and Innovative Team of Agricultural Scientific Research, AoShan Talents Cultivation Program Supported by the Qingdao National Laboratory for Marine Science and Technology (No. 2017ASTCP-OS13), Dalian High Level Talent Innovation Support Program (2015R020), the Research Foundation for Talented Scholars in Dalian Ocean University to LW, the Distinguished Professor of Liaoning to LS, and the Research Foundation in Dalian Ocean University (HDYJ201806).

\section{ACKNOWLEDGMENTS}

We are grateful to all the members of the Marine Biology \& Biotechnology Laboratory of Dalian Ocean University for their technical advice and helpful discussions.

distinct from chitotriosidase. J. Biol. Chem. 276, 6770-6778. doi: 10.1074/jbc. m009886200

Boot, R. G., Renkema, G. H., Strijland, A., Van Zonneveld, A. J., and Aerts, J. M. (1995). Cloning of a cDNA encoding chitotriosidase, a human chitinase produced by macrophages. J. Biol. Chem. 270, 26252-26256. doi: 10.1074/jbc. 270.44.26252

Bulawa, C. E. (1992). CSD2, CSD3, and CSD4, genes required for chitin synthesis in Saccharomyces cerevisiae: the CSD2 gene product is related to chitin synthases and to developmentally regulated proteins in Rhizobium species and Xenopus laevis. Mol. Cell Biol. 12, 1764-1776. doi: 10.1128/mcb.12.4. 1764

Carriker, M. R., and Palmer, R. E. (1979). Ultrastructural morphogenesis of prodissoconch and early dissoconch valves of the oyster Crassostrea virginica. Proc. Natl. Shellfish Assoc. 69, 103-128.

Eyster, L. S. (1986). Shell inorganic composition and onset of shell mineralization during bivalve and gastropod embryogenesis. Biol. Bull. 170, 211-231. doi: $10.2307 / 1541804$ 
Eyster, L. S., and Morse, M. P. (1984). Early shell formation during molluscan embryogenesis, with new studies on the surf clam. Spisula-Solidissima. Am. Zool. 24, 871-882. doi: 10.1093/icb/24.4.871

Gao, L., Xu, G. J., Su, H., Gao, X. G., Li, Y. F., Bao, X. B., et al. (2014). Identification and expression analysis of cDNA encoding chitinase-like protein (CLP) gene in Japanese scallop Mizuhopecten yessoensis. Genet. Mol. Res.13, 10727-10740. doi: 10.4238/2014.December.18.14

Gazeau, F., Gattuso, J. P., Dawber, C., Pronker, A. E., Peene, F., Peene, J., et al. (2010). Effect of ocean acidification on the early life stages of the blue mussel Mytilus edulis. Biogeosciences 7, 2051-2060. doi: 10.1080/15287394. 2011.550460

Hendriks, I. E., Duarte, C. M., Olsen, Y. S., Steckbauer, A., Ramajo, L., Moore, T. S., et al. (2015). Biological mechanisms supporting adaptation to ocean acidification in coastal ecosystems. Estuar. Coast. Shelf. S 152, A1-A8.

Kerr, R. A. (2010). Ocean acidification unprecedented, unsettling. Science 328, 1500-1501. doi: 10.1126/science.328.5985.1500

Kin, K., Kakoi, S., and Wada, H. (2009). A novel role for dpp in the shaping of bivalve shells revealed in a conserved molluscan developmental program. Dev. Biol. 329, 152-166. doi: 10.1016/j.ydbio.2009.01.021

Kniprath, E. (1979). Functional-morphology of the embryonic shell-gland in the conchiferous mollusks. Malacologia 18, 549-552.

Kniprath, E. (1981). Ontogeny of the molluscan shell field - a review. Zool. Scr. 10, 61-79. doi: 10.1111/j.1463-6409.1981.tb00485.x

Kroeker, K. J., Kordas, R. L., Crim, R. N., and Singh, G. G. (2010). Meta-analysis reveals negative yet variable effects of ocean acidification on marine organisms. Ecol. Lett. 13, 1419-1434. doi: 10.1111/j.1461-0248.2010.01518.x

Kurihara, H., Kato, S., and Ishimatsu, A. (2007). Effects of increased seawater pCO2 on early development of the oyster Crassostrea gigas. Aquat. Biol. 1, 91-98. doi: 10.3354/ab00009

Lannig, G., Eilers, S., Pörtner, H. O., Sokolova, I. M., and Bock, C. (2010). Impact of ocean acidification on energy metabolism of oyster, Crassostrea gigas - changes in metabolic pathways and thermal response. Mar. Drugs 8, 2318-2339. doi: $10.3390 / \mathrm{md} 8082318$

Levi-Kalisman, Y., Falini, G., Addadi, L., and Weiner, S. (2001). Structure of the nacreous organic matrix of a bivalve mollusk shell examined in the hydrated state using cryo-TEM. J. Struct. Biol. 135, 8-17. doi: 10.1006/jsbi.2001.4372

Li, H., Wang, D., Deng, Z., Huang, G., Fan, S., Zhou, D., et al. (2017). Molecular characterization and expression analysis of chitinase from the pearl oyster Pinctada fucata. Comp. Biochem. Physiol. B Biochem. Mol. Biol. 203, 141-148. doi: 10.1016/j.cbpb.2016.10.007

Liu, Z., Wang, L., Yan, Y., Zheng, Y., Ge, W., Li, M., et al. (2018). D1 dopamine receptor is involved in shell formation in larvae of Pacific oyster Crassostrea gigas. Dev. Comp. Immunol. 84, 337-342. doi: 10.1016/j.dci.2018.03.009

Livak, K. J., and Schmittgen, T. D. (2001). Analysis of relative gene expression data using real-time quantitative PCR and the 2- $\Delta \Delta$ CT method. Methods 25 , 402-408. doi: 10.1006/meth.2001.1262

Luo, Y. J., Takeuchi, T., Koyanagi, R., Yamada, L., Kanda, M., Khalturina, M., et al. (2015). The Lingula genome provides insights into brachiopod evolution and the origin of phosphate biomineralization. Nat. Commun. 6:8301. doi: 10.1038/ ncomms9301

Mali, B., Mohrlen, F., Frohme, M., and Frank, U. (2004). A putative double role of a chitinase in a cnidarian: pattern formation and immunity. Dev. Comp. Immunol. 28, 973-981. doi: 10.1016/j.dci.2004.04.002

Marin, F., Le Roy, N., and Marie, B. (2012). The formation and mineralization of mollusk shell. Front. Biosci. 4:1099-1125. doi: 10.2741/s321

Marin, F., Luquet, G., Marie, B., and Medakovic, D. (2008). Molluscan shell proteins: primary structure, origin, and evolution. Curr. Top. Dev. Biol. 80, 209-276. doi: 10.1016/s0070-2153(07)80006-8

McDonald, M. R., Mcclintock, J. B., Amsler, C. D., Rittschof, D., Angus, R. A., Orihuela, B., et al. (2009). Effects of ocean acidification over the life history of the barnacle Amphibalanus amphitrite. Mar. Ecil. Prog. Ser. 385, 179-187. doi: 10.3354/meps08099

Miller, A. W., Reynolds, A. C., Sobrino, C., and Riedel, G. F. (2009). Shellfish face uncertain future in high $\mathrm{CO} 2$ world: influence of acidification on oyster larvae calcification and growth in estuaries. PLoS One 4:e5661. doi: 10.1371/journal. pone. 0005661

Nudelman, F., Gotliv, B. A., Addadi, L., and Weiner, S. (2006). Mollusk shell formation: mapping the distribution of organic matrix components underlying a single aragonitic tablet in nacre. J. Struct. Biol. 153, 176-187. doi: 10.1016/j. jsb.2005.09.009

Orr, J. C., Fabry, V. J., Aumont, O., Bopp, L., Doney, S. C., Feely, R. A., et al. (2005). Anthropogenic ocean acidification over the twenty-first century and its impact on calcifying organisms. Nature 437, 681-686. doi: 10.1038/nature04095

Parker, L. M., Ross, P. M., O'connor, W. A., Borysko, L., Raftos, D. A., and Pörtner, H. (2012). Adult exposure influences offspring response to ocean acidification in oysters. Global. Change. Biol. 18, 82-92. doi: 10.1111/j.1365-2486.2011. 02520.x

Peters, W. (1972). Occurence of chitin in mollusca. Biochem. Bioph. Res. Co. 41, 541-550. doi: 10.1016/0305-0491(72)90117-4

Renkema, G. H., Boot, R. G., Muijsers, A. O., Donker-Koopman, W. E., and Aerts, J. M. (1995). Purification and characterization of human chitotriosidase, a novel member of the chitinase family of proteins. J. Biol. Chem. 270, 2198-2202. doi: $10.1074 /$ jbc. 270.5 .2198

Sabine, C. L., Feely, R. A., Gruber, N., Key, R. M., Lee, K., Bullister, J. L., et al. (2004). The oceanic sink for anthropogenic CO2. Science 305, 367-371. doi: $10.1126 /$ science. 1097403

Sburlati, A., and Cabib, E. (1986). Chitin synthetase 2, a presumptive participant in septum formation in Saccharomyces cerevisiae. J. Biol. Chem. 261, 1514715152.

Schonitzer, V., Eichner, N., Clausen-Schaumann, H., and Weiss, I. M. (2011). Transmembrane myosin chitin synthase involved in mollusc shell formation produced in dictyostelium is active. Biochem. Biophys. Res. Commun. 415, 586-590. doi: 10.1016/j.bbrc.2011.10.109

Schonitzer, V., and Weiss, I. M. (2007). The structure of mollusc larval shells formed in the presence of the chitin synthase inhibitor nikkomycin Z. BMC Struct. Biol. 7:71. doi: 10.1186/1472-6807-7-71

Schönitzer, V., and Weiss, I. M. (2007). The structure of mollusc larval shells formed in the presence of the chitin synthase inhibitor nikkomycin Z. BMC Struct. Biol. 7:71. doi: 10.1186/1472-6807-7-71

Talmage, S. C., and Gobler, C. J. (2009). The effects of elevated carbon dioxide concentrations on the metamorphosis, size, and survival of larval hard clams (Mercenaria mercenaria), bay scallops (Argopecten irradians), and Eastern oysters (Crassostrea virginica). Limno. Oceanogr. 54, 2072-2080. doi: 10.4319/ lo.2009.54.6.2072

Talmage, S. C., and Gobler, C. J. (2010). Effects of past, present, and future ocean carbon dioxide concentrations on the growth and survival of larval shellfish. Proc. Natl. Acad. Sci. U.S.A. 107, 17246-17251. doi: 10.1073/pnas.0913804107

Thisse, C., and Thisse, B. (2008). High-resolution in situ hybridization to wholemount zebrafish embryos. Nat. Protoc. 3, 59-69. doi: 10.1038/nprot.2007.514

Waldbusser, G. G., Brunner, E. L., Haley, B. A., Hales, B., Langdon, C. J., and Prahl, F. G. (2013). A developmental and energetic basis linking larval oyster shell formation to acidification sensitivity. Geophys. Res. Lett. 40, 2171-2176. doi: $10.1002 /$ grl.50449

Waldbusser, G. G., Hales, B., Langdon, C. J., Haley, B. A., Schrader, P., Brunner, E. L., et al. (2014). Saturation-state sensitivity of marine bivalve larvae to ocean acidification. Nat. Clim. Chang. 5, 273-280. doi: 10.1038/nclimate2479

Waldbusser, G. G., and Salisbury, J. E. (2014). Ocean acidification in the coastal zone from an organism's perspective: multiple system parameters, frequency domains, and habitats. Ann. Rev. Mar. Sci. 6, 221-247. doi: 10.1146/annurevmarine-121211-172238

Waller, T. R. (1981). Functional morphology and development of veliger larvae of the European oyster, Ostrea edulis Linne. Smithsonian. Contrib. Zool. 328, 1-70. doi: $10.5479 /$ si.00810282.328

Weiss, I. M., and Schonitzer, V. (2006). The distribution of chitin in larval shells of the bivalve mollusk Mytilus galloprovincialis. J. Struct. Biol. 153, 264-277. doi: 10.1016/j.jsb.2005.11.006

Weiss, I. M., Schonitzer, V., Eichner, N., and Sumper, M. (2006). The chitin synthase involved in marine bivalve mollusk shell formation contains a myosin domain. FEBS Lett. 580, 1846-1852. doi: 10.1016/j.febslet.2006.02.044

Weiss, I. M., Tuross, N., Addadi, L., and Weiner, S. (2002). Mollusc larval shell formation: amorphous calcium carbonate is a precursor phase for aragonite. J. Exp. Zool. 293, 478-491. doi: 10.1002/jez.90004

Zentz, F., Bedouet, L., Almeida, M. J., Milet, C., Lopez, E., and Giraud, M. (2001). Characterization and quantification of chitosan extracted from nacre of the abalone Haliotis tuberculata and the oyster Pinctada maxima. Mar. Biotechnol. 3, 36-44. doi: 10.1007/s101260000042 
Zhang, G., Fang, X., Guo, X., Li, L., Luo, R., Xu, F., et al. (2012). The oyster genome reveals stress adaptation and complexity of shell formation. Nature 490, 49-54. doi: $10.1038 /$ nature 11413

Zhang, H., Song, L., Li, C., Zhao, J., Wang, H., Qiu, L., et al. (2008). A novel Clq-domain-containing protein from Zhikong scallop Chlamys farreri with lipopolysaccharide binding activity. Fish. Shellfish Immunol. 25, 281-289. doi: 10.1016/j.fsi.2008.06.003

Zhao, X., Shi, W., Han, Y., Liu, S., Guo, C., Fu, W., et al. (2017). Ocean acidification adversely influences metabolism, extracellular $\mathrm{pH}$ and calcification of an economically important marine bivalve. Tegillarca granosa. Mar. Environ. Res. 125, 82-89. doi: 10.1016/j.marenvres.2017.01.007

Zhou, Z., Wang, L., Shi, X., Yue, F., Wang, M., Zhang, H., et al. (2012). The expression of dopa decarboxylase and dopamine beta hydroxylase and their responding to bacterial challenge during the ontogenesis of scallop Chlamys farreri. Fish. Shellfish Immunol. 33, 67-74. doi: 10.1016/j.fsi.2012.04.002

Conflict of Interest Statement: The authors declare that the research was conducted in the absence of any commercial or financial relationships that could be construed as a potential conflict of interest.

Copyright (c) 2019 Zhang, Liu, Song, Huang, Wang and Song. This is an open-access article distributed under the terms of the Creative Commons Attribution License (CC BY). The use, distribution or reproduction in other forums is permitted, provided the original author(s) and the copyright owner(s) are credited and that the original publication in this journal is cited, in accordance with accepted academic practice. No use, distribution or reproduction is permitted which does not comply with these terms. 